\title{
Factors related to survival outcomes following orbital exenteration: a retrospective, comparative, case series
}

\author{
Orapan Aryasit (1D, Passorn Preechawai, Chakree Hirunpat, Orasa Horatanaruang and Penny Singha
}

\begin{abstract}
Background: Orbital exenteration is a disfiguring procedure that aims to achieve local control. It is commonly a part of the management of malignant orbital tumor which is a life-threatening condition. It is necessary to determine predictive factors associated with overall survival (OS) following orbital exenteration.

Methods: This was a retrospective, comparative, case series of 39 patients with malignant tumors who underwent orbital exenteration. Patient records were reviewed for age, clinical presentation, preoperative visual acuity (VA), tumor size, surgical margin, tumor invasiveness, recurrent disease, and status of distant metastasis. Kaplan-Meier curves were used to assess OS and event-free survival (EFS). The predictive factors related to OS were identified using multivariate analysis.

Results: The mean age was 62.9 years (range, 5.5 to 89.7 years), 68.4\% presented with VA $<20 / 400$. The mean size of all tumors was $32 \pm 18 \mathrm{~mm}$. Distant metastasis at diagnosis was reported in 11 patients (28.2\%). Twenty-two patients died during follow-up. The median OS and EFS were 3.89 years and 3.01 years, respectively. The predictive factors for worse OS on multivariate analysis were preoperative VA $<20 / 400$ (adjusted hazard ratio [aHR] 4.67, $P=0.003$ ), tumor size larger than $20 \mathrm{~mm}$ (aHR 3.14, $P=0.022$ ) and positive distant metastasis at diagnosis (aHR 15.31, $P<0.001$ ).

Conclusions: The prognostic factors for poor survival outcome following orbital exenteration were a preoperative VA $<20 / 400$, tumor size $>20 \mathrm{~mm}$, and distant metastasis at diagnosis mostly due to patient negligence.
\end{abstract}

Keywords: Orbital exenteration, Predictive factor, Metastasis, Overall survival

\section{Background}

Orbital exenteration is a disfiguring procedure which removes all of the orbital contents including the periosteum and eyelids with or without the orbital bone. Modern exenteration was first described by George Bartisch in 1583 (cited by Goldberg et al. [1]). A number of diseases require orbital exenteration to achieve local control; for example, destructive tumors that have spread to the orbit, lacrimal gland malignancies, and fungal infections. About $50 \%$ of exenteration cases originate from the eyelids or periocular skin $[1,2]$.

Most publications on predictive factors associated with survival outcomes following orbital exenteration were reported from developed countries. Wong et al. reported

\footnotetext{
* Correspondence: all_or_none22781@hotmail.com

Department of Ophthalmology, Faculty of Medicine, Prince of Songkla

University, 15, Kanjanavanich Rd, Kohong, Hat Yai, Songkhla 90110, Thailand
}

that survival was significantly more closely related to the histopathological diagnosis (mostly basal cell carcinoma) than surgical margins [3]. Otherwise, positive final surgical margin had a poor prognosis in patients who underwent orbital exenteration for advanced periorbital skin cancer [4]. In addition, bone erosion and perineural invasion were the predictive factors for poor survival of orbital exenteration $[4,5]$.

The goal of our study was to examine the predictive factors related to overall survival (OS) following orbital exenteration in patients with malignancy. We considered the following factors that could predict survival: age, presenting symptoms and their duration, preoperative visual acuity (VA), tumor size (greatest dimension of the lesion in millimeters), histopathological diagnosis, surgical margin, tumor invasiveness (lymphovascular, perineural, bony), recurrent disease, and status of metastasis.

(C) The Author(s). 2018 Open Access This article is distributed under the terms of the Creative Commons Attribution 4.0 International License (http://creativecommons.org/licenses/by/4.0/), which permits unrestricted use, distribution, and 


\section{Methods}

\section{Study design}

This retrospective study included patients admitted for total or extended orbital exenteration performed between January 2006 and February 2016 at Songklanagarind Hospital which is a major tertiary-care center and university hospital in southern Thailand. Approval was obtained from the Ethics Committee of the Faculty of Medicine, Prince of Songkla University, and this study adhered to the tenets of the Declaration of Helsinki. We excluded patients with non-malignancy who underwent orbital exenteration.

\section{Data collection}

Patient records were reviewed for age, gender, presenting symptoms and their duration, preoperative VA after referral from a primary or secondary care center, indication for surgery, tumor origin, tumor size, histopathological diagnosis, surgical margin, tumor invasiveness (lymphovascular, perineural, bony), status of distant metastasis, surgical complications, recurrent disease, date of death (if applicable), and cause of death of deceased patients. We defined a large tumor as $>20 \mathrm{~mm}$ in greatest dimension. Poor preoperative VA was defined as $<20 / 400$ using the WHO blindness classification [6] as a potential predictive factor affecting OS.

\section{Statistical analysis}

Data were analyzed using Stata Statistical Software (STATA MP 14.1. StataCorp LP). Event-free survival (EFS) was measured from the date of orbital exenteration to recurrent disease or death due to any cause. OS was defined as the date of orbital exenteration until last follow-up or death. Patients without an event or death were censored at the time of last known follow-up or May 1, 2017. VA loss, large tumor, extraocular muscle involvement, tumor invasiveness, unclear surgical margin, recurrent disease, and distant metastasis at diagnosis were the factors used in the Kaplan Meier analysis with a confidence interval [7]. The log-rank test was used to potentially predict a poor prognosis for OS. The Mann-Whitney U test was also used for the statistical analysis.

Multivariate models were constructed including minimal sets of adjustment variables indicated by a directed acyclic graph using DAGitty Version 3.0 (Johannes Textor, Utrecht University, The Netherlands) to minimize bias in the estimation. The causal diagram between the variables of interest and covariables was created based on causal assumptions, and the total effect of influencing survival was reported. Cox proportional hazards models were used to analyze the predictive factors for survival outcomes following orbital exenteration. A $P$ value < 0.05 was considered to indicate statistical significance.

\section{Results}

\section{Patient data and histopathologic diagnosis}

From a total of 41 patients who underwent orbital exenteration over the study period, only 2 patients were excluded: 1 invasive aspergillosis and 1 mucormycosis. Thirty-nine patients (21 males, 18 females) were enrolled in the study with a mean age of $62.9 \pm 20.4$ years (range, 5.5 to 89.7 years). Fourteen different tumors were identified (Table 1). The most common tumor origins in the exenterated patients were the conjunctiva and the eyelids. In addition, 14 patients ( 9 males and 5 females) with a mean age of 67.1 years were diagnosed with squamous cell carcinoma. The most common presenting symptoms and signs were restriction of extraocular movement $(74.4 \%)$, followed by blurry vision (68.4\%), mass $(66.7 \%)$, and eye pain $(41.0 \%)$. Eleven patients with distant metastasis had blurry vision $(81.8 \%)$ and eye pain (45.5\%).

The preoperative VA was equal to or better than 20/ 400 in 12 , less than $20 / 400$ to light perception in 13 , no light perception in 13, and no data available in 1 case. The mean tumor size was $32 \pm 18 \mathrm{~mm}$ (range, 10 to $100 \mathrm{~mm}$ ), and mean duration of presenting symptoms was 67.9 weeks (range, 4.3 weeks to 6.0 years). Five patients had regional nodal metastasis at initial diagnosis. Distant metastases were detected in 11 patients (liver in 3, brain in 2 , lung in 2 , bone in 2 , and multiple sites in 2 ) that consisted of 3 squamous cell carcinomas, 3 malignant melanomas, 3 adenoid cystic carcinomas, 1 retinoblastoma, and 1 apocrine carcinoma. The median sizes of tumor in the non-metastasis group versus metastasis group were $27.5 \mathrm{~mm}$ and $35 \mathrm{~mm}$, respectively, but the difference between the groups was not statistically significant

Table 1 Tissue origin and histological diagnosis of 39 exenterated cases

\begin{tabular}{lll}
\hline Origin & Histological diagnosis & Number of cases \\
\hline Conjunctiva & Squamous cell carcinoma & 11 \\
& Malignant melanoma & 1 \\
& Mucoepidermoid carcinoma & 1 \\
Eyelid & Squamous cell carcinoma & 3 \\
& Sebaceous cell carcinoma & 3 \\
& Basal cell carcinoma & 2 \\
& Malignant melanoma & 2 \\
Lacrimal gland & Adenocarcinoma & 2 \\
& Adenoid cystic carcinoma & 5 \\
Globe & Adenocarcinoma & 1 \\
& Choroidal melanoma & 2 \\
Orbit & Retinoblastoma & 2 \\
& Malignant fibrous histiocytoma & 3 \\
\hline
\end{tabular}


$(P=0.332)$. Of the 39 patients, 32 patients had neglected their disease, 4 had delayed initial diagnosis, and only 3 underwent primary treatment before orbital exenteration.

\section{Treatment modalities and outcome}

Of the 39 patients, 31 underwent total orbital exenteration and 8 underwent extended orbital exenteration. Six patients underwent additional resection: 2 parotidectomies, 1 neck node dissection, 1 craniofacial surgery, 1 maxillectomy, 1 ethmoidectomy, and 1 lateral rhinectomy. The orbital reconstructions involved 23 skin grafts, 12 bare bones, and 4 local flaps. Ten patients received only postoperative radiation, 7 received combined chemoradiation, and 1 received only chemotherapy.

Seven patients experienced recurrence at the mean time of 34.7 weeks (range, 10.4 weeks to 1.38 years) with a mean follow-up time of 3.1 years (range, 1.6 months to 12.0 years). Seventeen patients were living and 22 had died. Deaths in 3 patients were unrelated to the tumor. The median OS and EFS of all exenterated patients were 3.89 years and 3.01 years, respectively. The Kaplan-Meier estimates for OS at 1,3 , and 5 years were $69.1 \%, 50.5 \%$, and $41.1 \%$, respectively (Fig. 1a). The EFS at 1, 3, and 5 years were $66.6 \%, 47.5 \%$, and $37.8 \%$, respectively (Fig. $1 \mathrm{~b}$ ).

The log-rank test was used to identify variables significantly associated with OS (Table 2). The prognostic factors that could significantly predict inferior survival outcome in our study using univariate analysis were preoperative VA $<20 / 400(P=0.018)$, tumor size $>20 \mathrm{~mm}$ $(P=0.032)$, distant metastasis at diagnosis $(P<0.001)$, and recurrent disease $(P=0.043)$.

A clear surgical margin was obtained in 25 cases (64.1\%). Of these, 4 cases had regional nodal metastasis and 6 had distant metastasis at initial diagnosis. Fourteen patients were reported to have an unclear surgical margin (6/6 lacrimal gland, $3 / 4$ orbit, $3 / 13$ conjunctiva, $2 / 12$ eyelid). The OS rates for clear surgical margins at 1 and 5 years were $68.0 \%$ and $35.3 \%$, respectively. We also analyzed the OS for unclear surgical margins at 1 and 5 years and the results were $71.4 \%$ and $39.1 \%$, respectively.

The 1-year and 5-year OS rates were $91.7 \%$ and $68.8 \%$, respectively, for patients with preoperative VA $\geq 20 / 400$ which were superior compared with VA $<20 / 400$ (Fig. 2a). The Kaplan-Meier estimates for OS for tumor size $>20 \mathrm{~mm}$ at 1 and 5 years were $65.4 \%$ and $27.6 \%$, respectively, whereas for tumor size $\leq 20 \mathrm{~mm}$ at 1 and 5 years, the OS estimates were $76.2 \%$ and $67.7 \%$, respectively (Fig. 2b). Patients with distant metastasis at diagnosis had an inferior OS $(24.2 \%$ and $0 \%$ at 1 and 5 years, respectively) in comparison with patients without distant metastasis $(91.3 \%$ and $62.8 \%$ at 1 year and 5 years, respectively) (Fig. 2c). Recurrent disease was significantly associated with worse OS (Fig. 2d).

Multivariate analysis of OS revealed three predictive factors that were independently related to survival outcome following orbital exenteration: preoperative VA < 20/400 (adjusted hazard ratio [aHR] 4.67, 95\% confidence interval $[\mathrm{CI}] 1.27$ to $17.12, P=0.003)$, tumor size $>20 \mathrm{~mm}$ (aHR 3.14, 95\% CI 1.06 to $9.32, P=0.022$ ), and positive distant metastasis at diagnosis (aHR 15.31, 95\% CI 4.25 to $55.19, P<0.001$ ) (Table 3).

The OS rates of 14 patients with squamous cell carcinoma at 1,3 , and 5 years were $78.6 \%, 50.3 \%$, and $25.1 \%$, respectively. Distant metastasis at initial diagnosis and recurrent disease were significantly associated with worse OS of squamous cell carcinoma patients using the log-rank test $(P=0.001$ and $P=0.020$, respectively).

\section{Discussion}

This 10-year study found malignancies in 39 of 41 patients (95.1\%) who underwent an orbital exenteration. These results were similar to previously published data [8-11]. Before 1990, the most common histopathologic
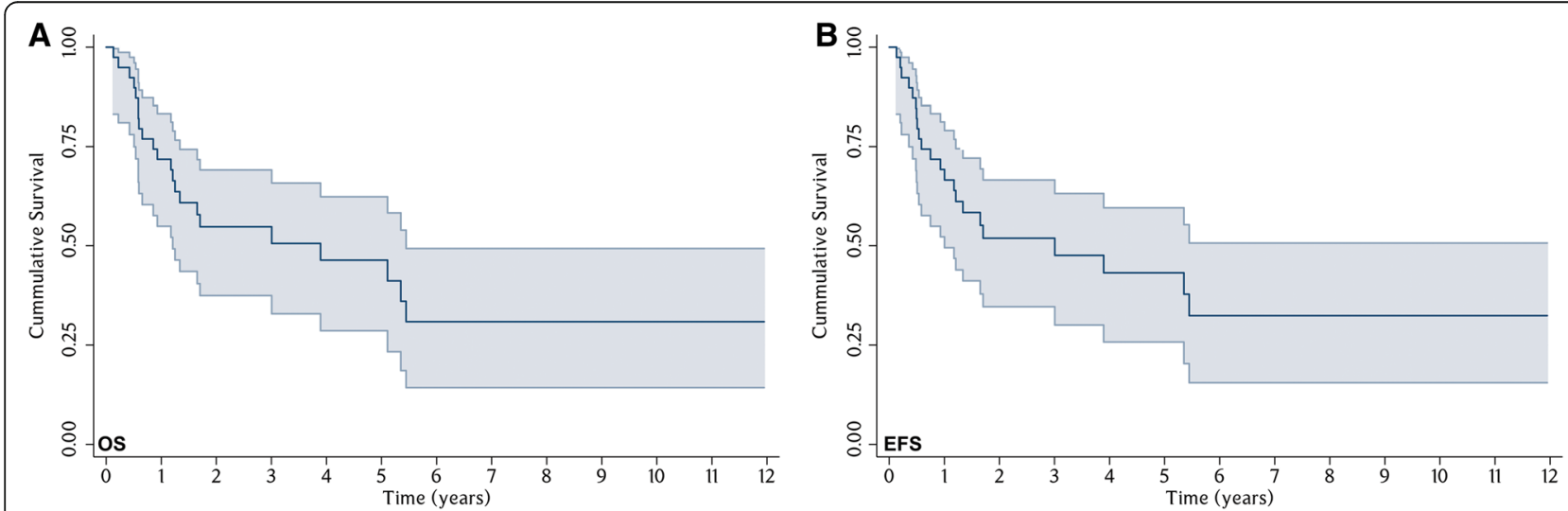

Fig. 1 Kaplan-Meier survival analysis for 39 cases: (a) Overall survival (OS). (b) Event-free survival (EFS). The shaded areas represent 95\% confidence interval (Cl) 
Table 2 Univariate analysis for various factors related to overall survival (OS)

\begin{tabular}{|c|c|c|c|c|c|c|}
\hline \multirow[t]{2}{*}{ Characteristic } & \multicolumn{5}{|c|}{ survival } & \multirow[t]{2}{*}{$P$ value } \\
\hline & $\mathrm{n} / \mathrm{N}$ & Median survival time (years) & 1 year (\%) & 3 years $(\%)$ & 5 years $(\%)$ & \\
\hline Overall rate & $22 / 39$ & 3.89 & 69.1 & 50.5 & 41.2 & \\
\hline \multicolumn{7}{|l|}{ Gender } \\
\hline Male & $11 / 21$ & 5.11 & 71.4 & 60.3 & 46.5 & \multirow[t]{2}{*}{0.269} \\
\hline Female & $11 / 18$ & 1.34 & 66.2 & 19.3 & 19.3 & \\
\hline \multicolumn{7}{|l|}{ Mean age (years) } \\
\hline$\leq 63$ & $11 / 18$ & 1.65 & 55.0 & 40.1 & 30.0 & \multirow[t]{2}{*}{0.516} \\
\hline$>63$ & $11 / 21$ & 5.35 & 76.2 & 51.9 & 41.5 & \\
\hline \multicolumn{7}{|c|}{ Mean duration of presenting symptom (weeks) } \\
\hline$\leq 67.9$ & $16 / 26$ & 3.89 & 65.2 & 51.8 & 41.5 & \multirow[t]{2}{*}{0.967} \\
\hline$>67.9$ & $6 / 13$ & 1.70 & 69.2 & 48.5 & 48.5 & \\
\hline \multicolumn{7}{|c|}{ Restriction of extraocular movements } \\
\hline No & $4 / 10$ & 5.35 & 90.0 & 75.0 & 56.0 & \multirow[t]{2}{*}{0.093} \\
\hline Yes & $18 / 29$ & 1.65 & 58.0 & 36.2 & 29.0 & \\
\hline \multicolumn{7}{|l|}{ Mass } \\
\hline No & $6 / 13$ & 5.35 & 69.2 & 29.7 & 29.7 & \multirow[t]{2}{*}{0.965} \\
\hline Yes & $16 / 26$ & 3.01 & 69.2 & 49.0 & 37.8 & \\
\hline \multicolumn{7}{|l|}{ Eye pain on presentation } \\
\hline No & $13 / 23$ & 3.01 & 69.6 & 55.8 & 42.5 & \multirow[t]{2}{*}{0.646} \\
\hline Yes & $9 / 16$ & 3.89 & 68.8 & 40.1 & 20.1 & \\
\hline \multicolumn{7}{|l|}{ VA } \\
\hline$\geq 20 / 400$ & $3 / 12$ & 10.1 & 91.7 & 68.8 & 68.8 & \multirow[t]{2}{*}{$0.018^{*}$} \\
\hline$<20 / 400$ & $18 / 26$ & 1.65 & 57.4 & 38.1 & 30.5 & \\
\hline \multicolumn{7}{|l|}{ Tumor size } \\
\hline$\leq 20 \mathrm{~mm}$ & $4 / 13$ & 11.95 & 76.2 & 67.7 & 67.7 & \multirow[t]{2}{*}{$0.032^{*}$} \\
\hline$>20 \mathrm{~mm}$ & $18 / 26$ & 1.65 & 65.4 & 41.4 & 27.6 & \\
\hline \multicolumn{7}{|l|}{ Histopathologic diagnosis } \\
\hline Non-squamous cell carcinoma & $15 / 25$ & 3.01 & 63.8 & 43.8 & 37.6 & \multirow[t]{2}{*}{0.528} \\
\hline Squamous cell carcinoma & $7 / 14$ & 5.35 & 78.6 & 50.3 & 25.1 & \\
\hline \multicolumn{7}{|l|}{ Tumor origin } \\
\hline Lid & $6 / 12$ & 3.01 & 83.3 & 44.4 & 22.2 & \multirow[t]{3}{*}{0.660} \\
\hline Lacrimal, globe, and orbit & $8 / 14$ & 0.85 & 50.0 & 40.0 & 40.0 & \\
\hline Conjunctiva & $8 / 13$ & 5.11 & 69.2 & 52.8 & 39.6 & \\
\hline \multicolumn{7}{|l|}{ Surgical margins } \\
\hline Unclear margin & $7 / 14$ & 5.45 & 71.4 & 52.1 & 39.1 & 0.597 \\
\hline Clear margin & $15 / 25$ & 3.89 & 68.0 & 44.1 & 35.3 & \\
\hline Tumor invasiveness (lymphovascu & erineura & & & & & \\
\hline No & $15 / 29$ & 3.89 & 65.5 & 48.6 & 41.7 & 0.453 \\
\hline Yes & $7 / 10$ & 3.01 & 80.0 & 40.0 & 20.0 & \\
\hline Status of metastasis & & & & & & \\
\hline No distant metastasis & $9 / 23$ & 5.45 & 91.3 & 70.6 & 62.8 & $<0.001^{*}$ \\
\hline Regional nodal metastasis & $3 / 5$ & 3.01 & 60.0 & 60.0 & 0.0 & \\
\hline Distant metastasis & $10 / 11$ & 0.59 & 24.2 & 0.0 & 0.0 & \\
\hline
\end{tabular}


Table 2 Univariate analysis for various factors related to overall survival (OS) (Continued)

\begin{tabular}{|c|c|c|c|c|c|c|}
\hline \multirow[t]{2}{*}{ Characteristic } & \multicolumn{5}{|c|}{ survival } & \multirow[t]{2}{*}{$P$ value } \\
\hline & $n / N$ & Median survival time (years) & 1 year $(\%)$ & 3 years (\%) & 5 years (\%) & \\
\hline \multicolumn{7}{|c|}{ Adding resection } \\
\hline No & $18 / 33$ & 3.89 & 63.5 & 47.9 & 41.9 & \multirow[t]{2}{*}{0.815} \\
\hline Yes & $4 / 6$ & 3.01 & 83.3 & 33.3 & 0.0 & \\
\hline \multicolumn{7}{|l|}{ Radiation } \\
\hline No & $12 / 22$ & 3.89 & 72.7 & 52.0 & 36.4 & \multirow[t]{2}{*}{0.579} \\
\hline Yes & $10 / 17$ & 5.11 & 64.7 & 37.8 & 37.8 & \\
\hline \multicolumn{7}{|l|}{ Chemotherapy } \\
\hline No & $16 / 31$ & 3.89 & 77.3 & 53.5 & 41.3 & \multirow[t]{2}{*}{0.197} \\
\hline Yes & $6 / 8$ & 0.65 & 37.5 & 18.8 & 18.8 & \\
\hline \multicolumn{7}{|c|}{ Recurrent disease } \\
\hline No & $16 / 32$ & 5.35 & 74.9 & 55.5 & 44.1 & \multirow[t]{2}{*}{$0.043^{*}$} \\
\hline Yes & $6 / 7$ & 0.85 & 28.6 & 0.0 & 0.0 & \\
\hline
\end{tabular}

$n$ deceased patients, $N$ total patients, VA Visual acuity, ${ }^{*} P$ value $<0.05$

diagnosis in patients requiring orbital exenteration was basal cell carcinoma (23.1\% to $35.5 \%$ ) [12-14]. Of note, an increasing trend was reported in the cases of squamous cell carcinoma due to globe or periorbital invasion that could not be managed by a simple surgical excision which comprised $32.3 \%$ to $38.4 \%$ of all exenterated patients $[10,15,16]$.

Our study also reported the most common indication for orbital exenteration was squamous cell carcinoma in $34.1 \%$ (conjunctiva in 11 and eyelid in 3 ). We found a low proportion of basal cell carcinoma (5.1\%). Ali et al. reported that ocular surface squamous neoplasia (44.4\%) and sebaceous gland carcinoma (18.5\%) were the most common indications for orbital exenteration in India [17]. Ocular surface squamous neoplasia is predominant in Asian and African countries because of chronic sun exposure and agricultural occupations $[18,19]$. Of the 14 squamous cell carcinoma patients in our report, 64.3\% were males. Demographic data of the current study also suggested a male predominance and the mean
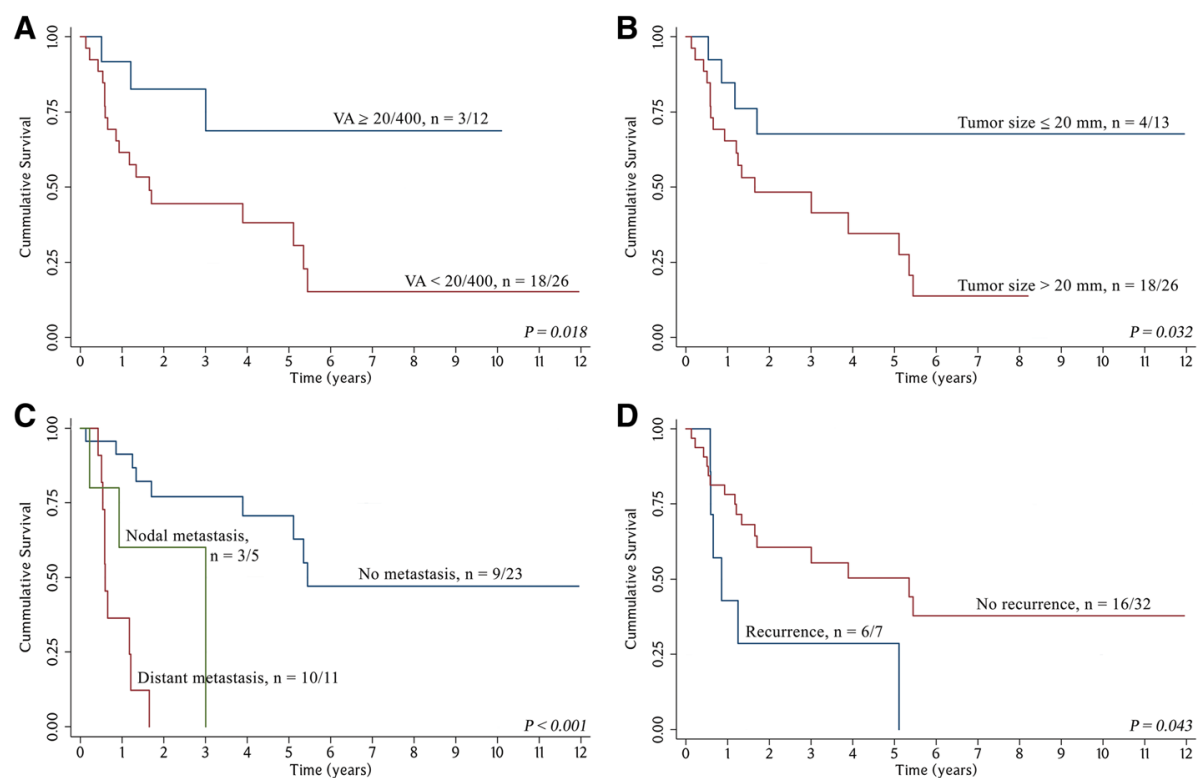

Fig. 2 Kaplan-Meier survival analysis for each group: (a) Overall survival (OS) for patients with VA 220/400 versus VA <20/400 (b) OS for patients with tumor size $\leq 20 \mathrm{~mm}$ versus tumor size $>20 \mathrm{~mm}$. (c) OS for patients with no distant metastasis, regional nodal metastasis versus distant metastasis. (d) OS for patients with or without recurrent disease 
Table 3 Multivariate analysis of predictors associated with overall survival (OS) showing total effect

\begin{tabular}{|c|c|c|c|c|}
\hline Variable & Minimally sufficient adjustment set & Exposure variable: Level & Adjusted Hazard Ratio (95\% Cl) & $P$ value \\
\hline \multirow[t]{2}{*}{ Mean age (years) } & & $\leq 63$ & 1 & \\
\hline & & $>63$ & $0.75(0.33,1.75)$ & 0.519 \\
\hline \multirow{2}{*}{$\begin{array}{l}\text { Mean duration of } \\
\text { presenting symptom } \\
\text { (weeks) }\end{array}$} & - Histopathologic diagnosis & $\leq 67.9$ & 1 & \\
\hline & & $>67.9$ & $1.19(0.41,3.45)$ & 0.751 \\
\hline \multirow[t]{3}{*}{$\begin{array}{l}\text { Restriction of extraocular } \\
\text { movements }\end{array}$} & $\begin{array}{l}\text { - Mean duration of presenting } \\
\text { symptom }\end{array}$ & No & 1 & \\
\hline & - Tumor invasiveness & Yes & $2.39(0.71,7.98)$ & 0.199 \\
\hline & - Tumor origin & & & \\
\hline \multirow[t]{2}{*}{ Mass } & & No & 1 & \\
\hline & & Yes & $1.02(0.40,2.64)$ & 0.965 \\
\hline \multirow[t]{2}{*}{ Eye pain on presentation } & - Histopathologic diagnosis & No & 1 & \\
\hline & & Yes & $1.40(0.56,3.48)$ & 0.476 \\
\hline \multirow[t]{4}{*}{ VA } & - Mean age & $\geq 20 / 400$ & 1 & \\
\hline & - Histopathologic diagnosis & $<20 / 400$ & $4.67(1.27,17.12)$ & $0.003^{*}$ \\
\hline & - Tumor origin & & & \\
\hline & - Tumor size & & & \\
\hline \multirow[t]{2}{*}{ Tumor size } & $\begin{array}{l}\text { - Mean duration of presenting } \\
\text { symptom }\end{array}$ & $\leq 20 \mathrm{~mm}$ & 1 & \\
\hline & - Histopathologic diagnosis & $>20 \mathrm{~mm}$ & $3.14(1.06,9.32)$ & $0.022^{*}$ \\
\hline \multirow[t]{2}{*}{ Histopathologic diagnosis } & - Mean age & Non-squamous cell & 1 & \\
\hline & - Tumor origin & Squamous cell & $0.58(0.15,2.30)$ & 0.435 \\
\hline \multirow[t]{5}{*}{ Tumor origin } & & Lid & 1 & \\
\hline & & Lacrimal, globe, and orbit & $1.57(0.54,4.59)$ & 0.674 \\
\hline & & Conjunctiva & $1.09(0.37,3.16)$ & \\
\hline & & Conjunctiva & 1 & \\
\hline & & Lacrimal, globe, and orbit & $1.44(0.53,3.91)$ & \\
\hline \multirow[t]{2}{*}{ Surgical margins } & & Clear margin & 1 & \\
\hline & & Unclear margin & $0.78(0.32,1.94)$ & 0.593 \\
\hline \multirow{2}{*}{$\begin{array}{l}\text { Tumor invasiveness } \\
\text { (lymphovascular, perineural, bony) }\end{array}$} & & No & 1 & \\
\hline & & Yes & $1.41(0.57,3.48)$ & 0.466 \\
\hline \multirow[t]{3}{*}{ Status of metastasis } & $\begin{array}{l}\text { - Mean duration of presenting } \\
\text { symptom }\end{array}$ & Negative & 1 & \\
\hline & - Histopathologic diagnosis & Regional nodal metastasis & $3.32(0.76,14.52)$ & $<0.001^{*}$ \\
\hline & - Tumor size & Distant metastasis & $15.31(4.25,55.19)$ & \\
\hline \multirow[t]{3}{*}{ Adding resection } & - Tumor invasiveness & No & 1 & \\
\hline & - Recurrent disease & Yes & $0.57(0.15,2.23)$ & 0.403 \\
\hline & - Surgical margins & & & \\
\hline \multirow[t]{2}{*}{ Radiation } & - Status of metastasis & No & 1 & \\
\hline & - Surgical margins & Yes & $1.27(0.45,3.56)$ & 0.654 \\
\hline \multirow[t]{2}{*}{ Chemotherapy } & - Status of metastasis & No & 1 & \\
\hline & & Yes & $1.76(0.63,4.93)$ & 0.298 \\
\hline \multirow[t]{2}{*}{ Recurrent disease } & & No & 1 & \\
\hline & & Yes & $2.62(0.99,6.91)$ & 0.070 \\
\hline
\end{tabular}


age of nearly 70 years in those patients with squamous cell carcinoma corresponded to the findings of prior studies [20,21]. Our study revealed a low rate of basal cell carcinoma in association with orbital exenteration. This might be due to the fact that basal cell carcinoma is a less aggressive tumor and the patient usually has time to recognize it.

Interestingly, we revealed that tumor-related survival was significantly better for patients with a preoperative VA $\geq 20 / 400$ than for patients with a VA $<20 / 400$. In addition, the common clinical presentation in our study was blurry vision which presented in nearly $70 \%$. Therefore, preoperative VA was one of the predictive factors related to OS. A possible reason for this is the origin of the tumor (i.e. the globe). For example, retinoblastoma and choroidal melanoma, which invade the sclera and involve the optic nerve or the orbit, are associated with a low rate of survival in spite of orbital exenteration [22-25]. A second reason is that malignant tumors of periorbital structures that affect the vision are typically invasive and highly aggressive in behavior. Even though the patient may have mild visual impairment in case of partial globe or optic nerve involvement, we recommend performing an orbital exenteration before the tumor advances further.

Although we were able to achieve local control with clear surgical margins in 25 patients (64.1\%), 10 of these patients had positive metastasis at initial diagnosis (4 patients had regional nodal metastasis [ 2 squamous cell carcinomas and 2 malignant melanomas] and 6 had distant metastasis [3 malignant melanomas, 2 squamous cell carcinomas, and 1 retinoblastoma]). Notably, we confirmed that the clear surgical margin group had a high rate of nodal or distant metastasis at diagnosis (40\%). The log-rank test revealed that clear versus unclear surgical margins did not show statistical significance in terms of OS $(P=0.597)$. Since a high proportion of metastasis was found in patients with clear surgical margins, we propose that micrometastasis occurred prior to orbital exenteration. However, surgical margins play an important role in controlling the site of the malignant tumors. Mouriaux et al. also reported that surgical margins significantly affected the control of local recurrence, which was not related to survival [15]. On the other hand, Gerring et al. reported that an unclear surgical margin was the only factor associated with a poor prognosis on multivariate analysis in patients undergoing orbital exenteration due to advanced periorbital non-melanoma skin cancer [4]. For the unclear surgical margin cases, adjuvant radiotherapy or chemotherapy or both increased the surgical cure rate $[9,10,26]$. Tumor invasiveness (lymphovascular, perineural, bony) was also not associated with a poor survival outcome which was contrary to the findings of previous studies $[8,27]$. However, it is important to recognize that our study had too few cases to detect statistical significance.
In this current study, tumor size greater than $20 \mathrm{~mm}$ at presentation was considered a large tumor and this significantly affected OS. Several studies of eye cancer also reported that larger tumor size posed a risk of local recurrence or metastasis which was possibly associated with the inferior survival outcome [28, 29]. Therefore, patient awareness and education is important to detect the disease in the early stage and receive proper management.

Distant metastasis at diagnosis is defined following the tumor-node-metastasis staging system and is associated with a poor overall prognosis. Therefore, distant metastasis was a predictive factor that helped estimate survival in our study, in which 11 of the 39 orbital exenterations had distant metastasis at diagnosis. The OS rates of the metastasis group were $81.8 \%$ and $24.2 \%$ at 6 months and 1 year, respectively. All patients with distant metastasis at diagnosis died within 1.65 years. The design of our study did not compare the OS between the patients who received only palliative chemoradiation without an orbital exenteration and the patients who underwent an orbital exenteration and adjuvant chemoradiation. Although orbital exenteration has the surgical goal of complete excision, it can improve local control to eliminate aggressive growth in the cases of a very large tumor and eye pain. However, in the metastasis group, the surgeon should discuss the choices of reconstruction and probably prefer a more conservative surgery.

The 5-year OS rate of all patients in our study was $41.2 \%$. This was lower compared to those of other studies because most of our patients in our study presented with large squamous cell carcinomas which pointed to patient negligence in treating the problem $[2,8,30]$.

One prior study revealed the OS rate of non-basal cell carcinoma (mostly, squamous cell carcinoma) at 5 years was $58 \%$ [3]. However, in the advanced age group with periorbital squamous cell carcinoma, the 1-year OS rate was only $50.5 \%$ [21]. The current study reported the OS rate of squamous cell carcinoma patients at 5 years which was also low (25.1\%). The possibility of death due to the histopathologic diagnosis was higher among squamous cell carcinoma patients who had distant metastasis at diagnosis or the recurrent disease or both.

A limitation of our study was its retrospective design. However, orbital exenteration is a rare procedure. During the study period, we performed only 4 cases per year in our institution. Therefore, conducting a prospective study would be difficult. Additionally, the short follow-up time limited our ability to identify the real number of cases with a local recurrence. The follow-up time needed is more than 3 years. Furthermore, this study included various histological types of tumors. Although, our study reported the OS of squamous cell carcinoma patients and two predictors that were significantly associated with 
worse prognosis, we were not able to classify the predictive factors affecting survival outcome for each histological type due to the small number of patients. The strength of this study is the information that it provides on predictive factors related to survival outcome of exenterated patients who have advanced tumors.

\section{Conclusions}

In summary, orbital exenteration can control local malignant tumors, but it is questionable in the treatment of cases with distant metastasis. The most common indication in our study was squamous cell carcinoma of the conjunctiva. Poor preoperative VA, larger tumor size, and distant metastasis were significantly associated with worse OS. Although a clear surgical margin was not related to survival, we recommend performing a clear surgical margin procedure and treating the early-stage disease, including cases with a small tumor size. The information on potential factors to predict OS may support patient counseling and the most effective treatment modality.

\section{Abbreviations}

aHR: adjusted hazard ratio; Cl: confidence interval; DAG: directed acyclic graph; EFS: event-free survival; LR: likelihood ratio; OS: overall survival;

SD: standard deviation; VA: visual acuity

\section{Acknowledgements}

The research was supported by grant from Faculty of Medicine, Prince of Songkla University. We would like to thank Dr. Alan Geater and Ms. Walailuk Jitphiboon for their valuable assistance regarding the statistics used in this project. We also would like to thank Ms. Parichat Damthongsuk for her assistance in collecting the data.

\section{Funding}

Faculty of Medicine, Prince of Songkla University.

\section{Availability of data and materials}

Available upon request from the corresponding author

\section{Authors' contributions}

Study concept and design: $\mathrm{OA}$ and PP; Acquisition of data: $\mathrm{OA}, \mathrm{PP}, \mathrm{CH}, \mathrm{OH}$, and PS; Analysis and interpretation of data: $\mathrm{OA}, \mathrm{PP}, \mathrm{CH}, \mathrm{OH}$, and PS; Drafting the manuscript: OA and PS; Revising the manuscript critically for important intellectual content: OA, PP, CH, OH, and PS; Study supervision: OA and PP. All authors had full access to all of the data in this study and take responsibility for the integrity of the data and the accuracy of the data analysis. All authors read and approved the final manuscript.

\section{Ethics approval and consent to participate}

The study was approved by the Ethics Committee of Faculty of Medicine, Prince of Songkla University, and this study adhered to the tenets of the Declaration of Helsinki. For this type of study formal consent was waived.

\section{Consent for publication}

Not applicable.

\section{Competing interests}

The authors declare that they have no competing interests.

\section{Publisher's Note}

Springer Nature remains neutral with regard to jurisdictional claims in published maps and institutional affiliations.
Received: 4 March 2018 Accepted: 16 July 2018

Published online: 28 July 2018

\section{References}

1. Goldberg RA, Kim JW, Shorr N. Orbital exenteration: results of an individualized approach. Ophthal Plast Reconstr Surg. 2003;19:229-36.

2. Ben Simon GJ, Schwarcz RM, Douglas R, Fiaschetti D, McCann JD, Goldberg RA. Orbital exenteration: one size does not fit all. Am J Ophthalmol. 2005; 139:11-7.

3. Wong JC, Thampy R, Cook A. Life expectancy following orbital exenteration. Br J Ophthalmol. 2015;99:1-4.

4. Gerring RC, Ott CT, Curry JM, Sargi ZB, Wester ST. Orbital exenteration for advanced periorbital non-melanoma skin cancer: prognostic factors and survival. Eye (Lond). 2017;31:379-88.

5. Limawararut V, Leibovitch I, Sullivan T, Selva D. Periocular squamous cell carcinoma. Clin Exp Ophthalmol. 2007;35:174-85.

6. World Health Organization. Change the definition of blindness, 2008. Accessed 2017 July 15. Available from: http://www.who.int/blindness/ Change\%20the\%20Definition\%20of\%20Blindness.pdf

7. Nilforushan N, Askari S, Karimi N. A common pitfall in glaucoma treatment success assessment. J Glaucoma. 2017;26:195-6.

8. Rahman I, Cook AE, Leatherbarrow B. Orbital exenteration: a 13 year Manchester experience. Br J Ophthalmol. 2005;89:1335-40.

9. Bartley GB, Garrity JA, Waller RR, Henderson JW, Ilstrup DM. Orbital exenteration at the Mayo Clinic. 1967-1986. Ophthalmology. 1989;96:468-73.

10. Levin PS, Dutton JJ. A 20-year series of orbital exenteration. Am J Ophthalmol. 1991;112:496-501.

11. Mohr C, Esser J. Orbital exenteration: surgical and reconstructive strategies. Graefes Arch Clin Exp Ophthalmol. 1997;235:288-95.

12. Rathbun JE, Beard C, Quickert MH. Evaluation of 48 cases of orbital exenteration. Am J Ophthalmol. 1971;72:191-9.

13. Simons JN, Robinson DW, Masters FW. Malignant tumours of the orbit and periorbital structures treated by exenteration. Plast Reconstr Surg. 1966;37: $100-4$.

14. de Conciliis C, Bonavolonta G. Incidence and treatment of dural exposure and CSF leak during orbital exenteration. Ophthal Plast Reconstr Surg. 1987; 3:61-4.

15. Mouriaux F, Martinot V, Pellerin P, Patenotre P, Rouland JF, Constantinides G. Survival after malignant tumours of the orbit and periorbit treated by exenteration. Acta Ophthalmol. 1999;77:326-30.

16. Pushker N, Kashyap S, Balasubramanya R, Bajaj MS, Sen S, Betharia SM, et al. Pattern of orbital exenteration in a tertiary eye care Centre in India. Clin Exp Ophthalmol. 2004:32:51-4.

17. Ali MJ, Pujari A, Dave TV, Kaliki S, Naik MN. Clinicopathological profile of orbital exenteration: 14 years of experience from a tertiary eye care center in South India. Int Ophthalmol. 2016;36:253-8.

18. Lee GA, Williams G, Hirst LW, Green AC. Risk factors in the development of ocular surface epithelial dysplasia. Ophthalmology. 1994;101:360-4.

19. Gichuhi S, Ohnuma S, Sagoo MS, Burton MJ. Pathophysiology of ocular surface squamous neoplasia. Exp Eye Res. 2014;129:172-82.

20. Sepulveda R, Pe'er J, Midena E, Seregard S, Dua HS, Singh AD. Topical chemotherapy for ocular surface squamous neoplasia: current status. $\mathrm{Br}$ J Ophthalmology. 2010;94:532-5.

21. Karabekmez FE, Selimoglu MN, Duymaz A, Karamese MS, Keskin M, Savaci N Management of neglected periorbital squamous cell carcinoma requiring orbital exenteration. J Craniofac Surg. 2014:25:729-34.

22. Kersten RC, Tse DT, Anderson RL, Blodi FC. The role of orbital exenteration in choroidal melanoma with extrascleral extension. Ophthalmology. 1985;92: 436-43.

23. Pach JM, Robertson DM, Taney BS, Martin JA, Campbell RJ, O'Brien PC. Prognostic factors in choroidal and ciliary body melanomas with extrascleral extension. Am J Ophthalmol. 1986:101:325-31.

24. Bergman L, Nilsson B, Lundell G, Lundell M, Seregard S. Ruthenium brachytherapy for uveal melanoma, 1979-2003: survival and functional outcomes in the Swedish population. Ophthalmology. 2005;112:834-40.

25. Radhakrishnan V, Kashyap S, Pushker N, Sharma S, Pathy S, Mohanti BK, et al. Outcome, pathologic findings, and compliance in orbital retinoblastoma (international retinoblastoma staging system stage III) treated with neoadjuvant chemotherapy: a prospective study. Ophthalmology. 2012;119: 1470-7. 
26. Shields JA, Shields CL, Freire JE, Brady LW, Komarnicky L. Plaque radiotherapy for selected orbital malignancies: preliminary observations: the 2002 Montgomery lecture, part 2. Ophthal Plast Reconstr Surg. 2003;19:91-5.

27. Tyers AG. Orbital exenteration for invasive skin tumours. Eye (Lond). 2006;20: $1165-70$.

28. Esmaeli B, Nasser QJ, Cruz H, Fellman M, Warneke CL, Ivan D. American joint committee on Cancer T category for eyelid sebaceous carcinoma correlates with nodal metastasis and survival. Ophthalmology. 2012;119:1078-82.

29. Nasser QJ, Roth KG, Warneke CL, Yin VT, El Sawy T, Esmaeli B. Impact of AJCC 'T' designation on risk of regional lymph node metastasis in patients with squamous carcinoma of the eyelid. Br J Ophthalmol. 2014;98:498-501.

30. Nemet AY, Martin P, Benger R, Kourt G, Sharma V, Ghabrial R, et al. Orbital exenteration: a 15-year study of 38 cases. Ophthal Plast Reconstr Surg. 2007; 23:468-72.

Ready to submit your research? Choose BMC and benefit from:

- fast, convenient online submission

- thorough peer review by experienced researchers in your field

- rapid publication on acceptance

- support for research data, including large and complex data types

- gold Open Access which fosters wider collaboration and increased citations

- maximum visibility for your research: over $100 \mathrm{M}$ website views per year

At $\mathrm{BMC}$, research is always in progress.

Learn more biomedcentral.com/submissions 